\author{
Military Technical College \\ Kobry Elkobbah, Cairo, \\ Egypt.
}

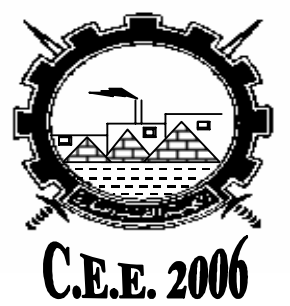

$3^{\text {rd }}$ International Conference

On

Chemical \& Environmental

Engineering

\title{
EFFECT OF ALUMINUM METAL IN DIFFERENT FORMS ON REDUCING THE THERMAL IMAGE OF A HOT PLATE
}

\author{
Abd-Elmagid M. K. *, Fayed M. Sh. * and ELKasaby M.A. *
}

\begin{abstract}
The advent of imaging seekers in the range of (8-12) $\mu \mathrm{m}$ band poses a new challenge in the area of infrared countermeasures. The application of camouflaging tent in this field is one of the effective methods which are used to decrease the thermal signature of the targets and hot bodies in the field.

In this paper a white duck textile barrier treated with white emulsion paint, aluminum metal in different forms was used to reduce the thermal image of hot plate $\left(100{ }^{\circ} \mathrm{C}\right)$. The effect of aluminum powder, aluminum spray, and aluminum foil on the reduction of the thermal image was studied. The results show that, as the aluminum powder content increase from 4.2 to $8.37 \mathrm{mg} / \mathrm{cm}^{2}$ the reduction in thermal image decreases from $90 \%$ to $87.3 \%$. However, for aluminum spray, as the areal density increases from $3.7 \mathrm{mg} / \mathrm{cm}^{2}$ to $11.1 \mathrm{mg} / \mathrm{cm}^{2}$ the percent reduction increases from $84 \%$ to $90 \%$. In addition to that, the application of a stream of air with volumetric flow rate of 1.2 lit/s between two identical samples improves this percent to $98.4 \%$. The results also show that, aluminum foil supported on white duck textile has the greatest effect, where it gives $99.7 \%$ percent reduction in the thermal image.
\end{abstract}

\section{KEY WORDS}

Thermal image, Aluminum.

\footnotetext{
* Egyptian Armed Forces.
} 


\section{INTRODUCTION}

Camouflage means to deceive and conceal the target and to minimize the possibility of its detection [1]. Generally this may be done by using some paints or textiles and other coverings, which have adequate properties to match with the surroundings so as to conceal the target.

The case of matching the infrared reflectance of surrounding such as foliage and inanimate objects, over the above wavelength range is dictated by the type of natural objects that make up the environment and the substrate to be concealed.

The reflectance of sand and soil show a slight and gradual rise from the levels in visible region to those in the infrared.

In order to blend in a target with its immediate environment, a stealth object must have a reflectance profile closely resembling its surroundings should be used.

Coating requirements to control radiation emissions from an object fall into two categories. The first: coating that absorbs or reflects the incident solar radiation. These coatings operate predominately in visible and near infrared region. The second: coating that controls emission resulting from the combination of incident solar radiation and thermal self-emitted radiation. These coatings operate in the visible and infrared regions.

The optical properties of paint films can be largely attributed to the type of pigments and additives present. Thus, application of surface coating techniques in the field of camouflage resulted in a need for information of the optical properties of pigments and additives in the infrared region [2].

Aluminum in different forms is used in this paper due to its high reflectance in the visible and infrared region [3].

\section{EXPERIMENTAL WORK}

\subsection{Paints and Chemicals.}

All paints and chemicals used in this work are of commercial grade. The paint composed of latex, $\mathrm{TiO}_{2}$, fillers and $\mathrm{H}_{2} \mathrm{O}$ produced by ISIPAC company. Aluminium spray, aluminium powdwer, and aluminium foil are used directly without any purification or treatment

\subsection{Experimental Set Up}

The set up used in this work consists of controled temperature hot plate, textile sample holder, air blower and a thermal imager model 760 LW. inframtrics $(8-12 \mu \mathrm{m})$ [4]. Treated samples are weighed by a digital balance type stanton with accuracy $0.01 \mathrm{~g}$. The setup is used to measure and record the thermal image of a hot plate controlled at temperature $100{ }^{\circ} \mathrm{C}$ with or without textile barrier as a function of time.

\subsection{Sample Preparation}

Known weight of aluminum powder is mixed with the emulsion paint and applied to a white duck textile sample and left for dryness. Aluminium spray was applied directily to the dry surface of painted white duck textile. The spray was left to dry in the open 
atmosphere. The sample of aluminium foil was prepared by placeing the foil in front of the dry painted white duck textile. The distances between the hot plate and the thermal imager was fixed to be $150 \mathrm{~cm}$ while the distance between the hot plate and the sample holder was $5 \mathrm{~cm}$. The data are collected,measured and recorded as mentioned in reference [5].

\section{RESULTS AND DISCUSSION}

\subsection{Effect Of Aluminum Powder Addition}

Aluminum powder is added to the paint by two concentrations, the first gives areal denstiy of $4.2 \mathrm{mg} / \mathrm{cm}^{2}$ and the second gives $8.37 \mathrm{mg} / \mathrm{cm}^{2}$. As the concentration of Al powder increases in the mixture, the paint becomes more thick and becomes more difficult to be applied on the textile surface. In addition, crakes starts to appear on the surface of the paint after drying. Also, the color of the paint is converted to gray. The sample placed at $5 \mathrm{~cm}$ distance from the hot plate with the treated surface facing it. The data are represented in Fig.1. It is shown from the figure that the temperature difference of the hot plate after the treated textile barrier and the background changes from 5 to 7.5 degrees at low areal density and from 5 to 9.6 degrees at high areal desity within the time interval of 20 minutes. These differences give reduction in the thermal image by $90 \%$ and $87 \%$ respectivily. This behaviour can be explained as follows. As the aluminium powder concentration increases in the sample, the heat content of the sample increases and its temperature increases. For this reason, the sample becomes more transparant in the infrared region. Consequently, the reduction in the thermal image of the hot plate decreases.

\subsection{Effect Of Aluminum Spray}

Aluminum spray is applied on the surface of textile sample with uniform distribution. Aluminum spray was selected due to its high reflectance properties. It is used with three different concentrations, $3.7 \mathrm{mg} / \mathrm{cm}^{2}, 7.4 \mathrm{mg} / \mathrm{cm}^{2}$, and $11.1 \mathrm{mg} / \mathrm{cm}^{2}$, respectivily. The color of aluminum spray on the textile did not give the silver appearance that characterizes aluminum spray. This may attributed to the absorption of the aluminum spray inside the textile surface and to the roughness of the textile surface. However, the application of aluminium spray on the treated textile with paint gives the required brightness. From Fig.2., it is clear that the temperature difference decrease as the concentration of Al spray increases on the textile surface. The changes of temperature difference in time interval of 60 minutes are from 3.3 to 8.1 , from 4.5 to 10.1 , and from 7.1 to 12 degrees for concentration of $11.1,7.4$, and 3.7 $\mathrm{mg} / \mathrm{cm}^{2}$ respectivily. These temperature differences coresponds to $89.2,86.5$, and 84.6 percent reduction of the thermal image of the hot plate This behaviour agrees with the theoritical studies since as the concentration of the spray increases, the brightness of the treated surface increases and the amount of radiation reflected increases. 


\subsection{Effect Of Air Flow Between Two Identical Samples}

The air flow passes between two idetical samples of textile painted with emulsion paint and aluminum spray. The distance between the two samples is $1 \mathrm{~cm}$. The distance between the first sample and the hot plate is $5 \mathrm{~cm}$. The treated face of samples is in the direction of the hot plate. The temperature of the hot plate is kept at $100{ }^{\circ} \mathrm{C}$. The air pass between the two samples in three different volumetric flow rates $0.77 \mathrm{lit} / \mathrm{s}, 0.98 \mathrm{lit} / \mathrm{s}$, and $1.2 \mathrm{lit} / \mathrm{s}$ respectivily. As shown in Fig.3., it is clear that, the temperature difference decreases as the volumetric flowrate of air increases. The temperature difference changes from 1.5 to 2.4 , from 1 to 1.9 , and from 0 to 1.2 degrees for volumetric flowrates of $0.77 \mathrm{lit} / \mathrm{s}, 0.98 \mathrm{lit} / \mathrm{s}$, and $1.2 \mathrm{lit} / \mathrm{s}$ respectivily. This effect of air flow can be explained as follows. As the air flows between the two samples,the air produces a partial distortion of the heat flux released from the hot plate and distribute it in a direction away from the view of IR camera. Consquently, the percent of thermal image reduction increased from $96.8 \%$ up to $98.4 \%$.

\subsection{Effect Of Aluminum Foil}

A single sheet of Al foil without any textile holder is used to measure its effect on the reduction of the thermal image of the hot plate. The data are presented in Fig 4. As shown from the figure, this sheet of $\mathrm{Al}$ foil produces a temperature difference of 0.2 ${ }^{\circ} \mathrm{C}$ which increased to $0.5^{\circ} \mathrm{C}$ in time interval of 20 minutes. These values coresponds to a reduction of thermal efficiency of $99.73 \%$ and $99.33 \%$ respectivily. However, this Al foil sheet has poor mechanical porperties and can not be used in the field alone without any textile support.

The same experiment was repeated by using the previous Al foil placed on the surface of a white duck textile treated with white emulsion paint. The results are shown in Fig 5. It is clear from the figure that this sheet of Al foil supported on the textile, produces a temperature difference of $0.1{ }^{\circ} \mathrm{C}$ which increased to $0.2{ }^{\circ} \mathrm{C}$ in time interval of 20 minutes. These values coresponds to a percent reduction in the thermal image by $99.87 \%$ and $99.73 \%$ respectivily.

\section{CONCLUSION}

Addition of aluminium powder to emulsion paint and its application on a white duck textile for the reduction of thermal image of a hot plate is not effective. However, white duck painted textile sample treated with aluminium spray reduces the thermal image of hot plate $\left(100^{\circ} \mathrm{C}\right)$ by $90 \%$. In addition, the application of a stream of air with volumetric flowrate $1.2 \mathrm{lit} / \mathrm{s}$ between two identical samples improves the percent reduction in to $98.4 \%$. Aluminum foil sheet placed on the surface of treated white duck textile gives the greatest effect on percent reduction of the thermal image of hot plate $(99.87 \%)$. 


\section{REFERENCES}

[5] J.C. Salamone "Concise Polymeric Materials Encyclopedia" CRC, 1995.

[6] K. K. GUPTA \& A. KISHKAM. "Camouflage in the Non-visible Region", Journal of INUSTRIAL TEXTILE, vol.31, No. 1- July 2001.

[7] Bechtold, Willi, Wenger, Adrian "Production of broad- band camouflage materials" Ger. Patent, DE 19816707.

[8] Inframetrics Inc. " IR Imaging Radiation Operation Manual Model Inframetrics 760", USA 1992.

[9] M. Sh. Fayed, M. Kassem, M. ELKasaby." Reduction of Thermal Image of a Hot Plate by Stealth Technology" $3^{\text {rd }}$ Int. Conf. 2006. (ACCEPTED). 


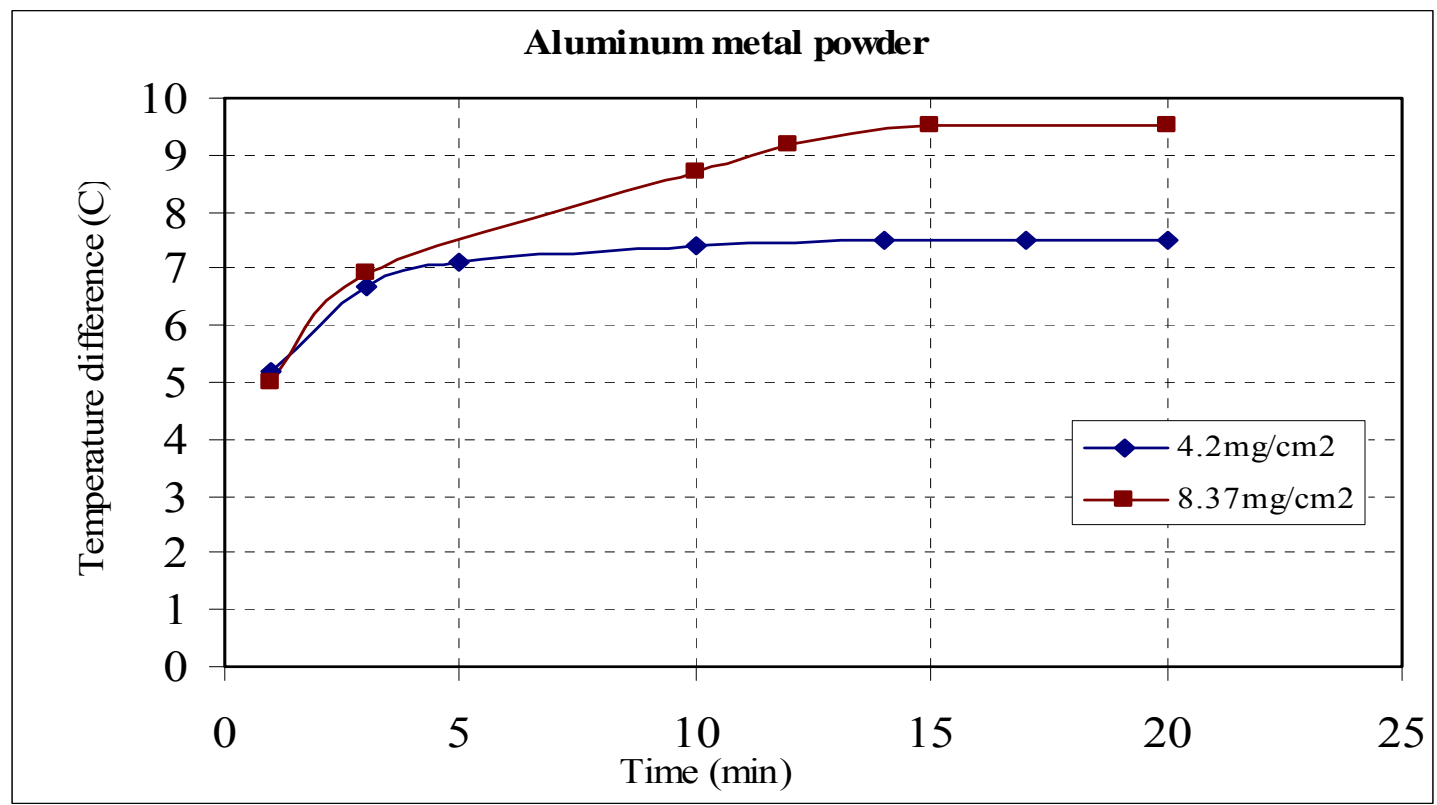

Fig.1. Effect of textile barrier treated with emulsion paint and different weights of Aluminum powder on temperature difference of a hot plate and background with time.

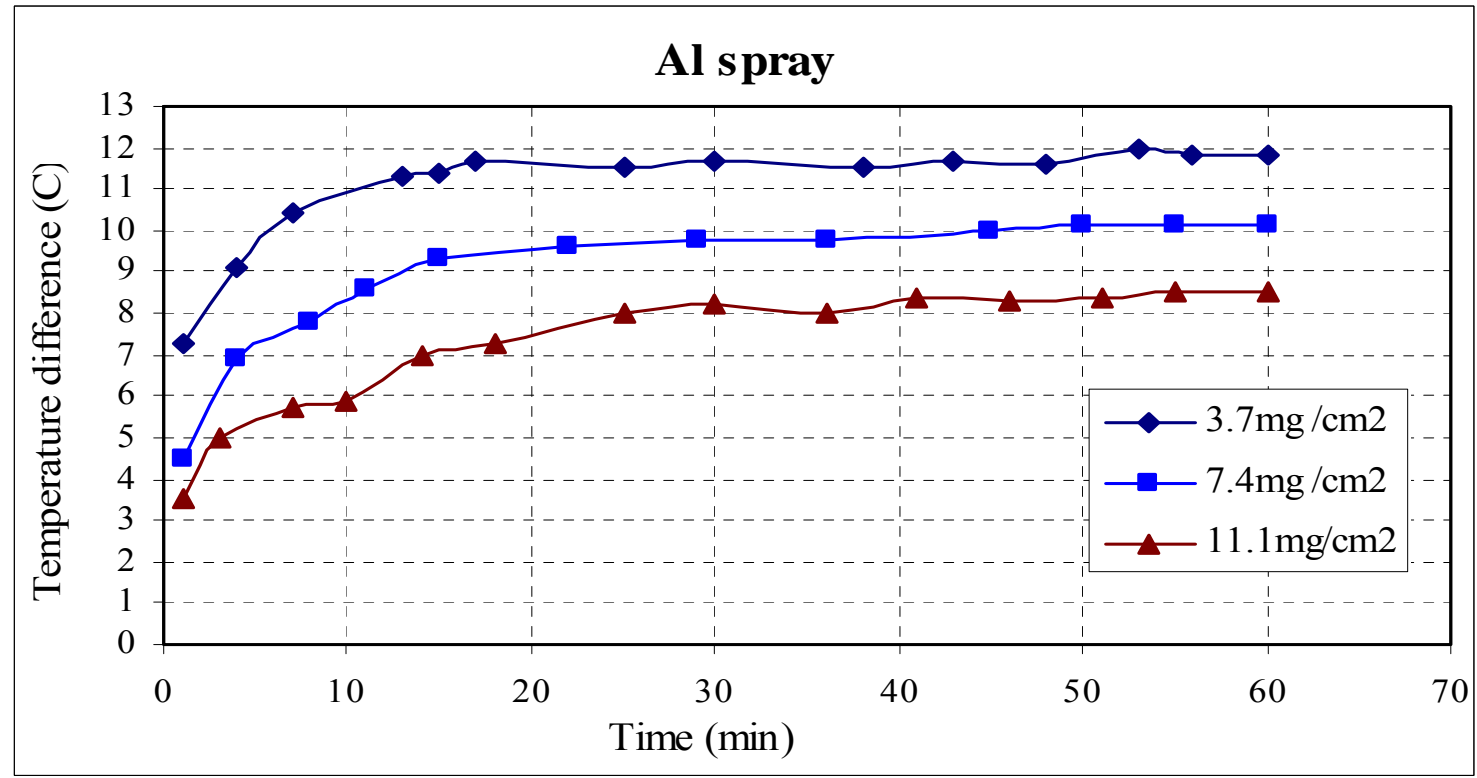

Fig.2.Effect of textile barrier treated with emulsion paint and different concentrations of Al spray on temperature difference of a hot plate and background with time. 


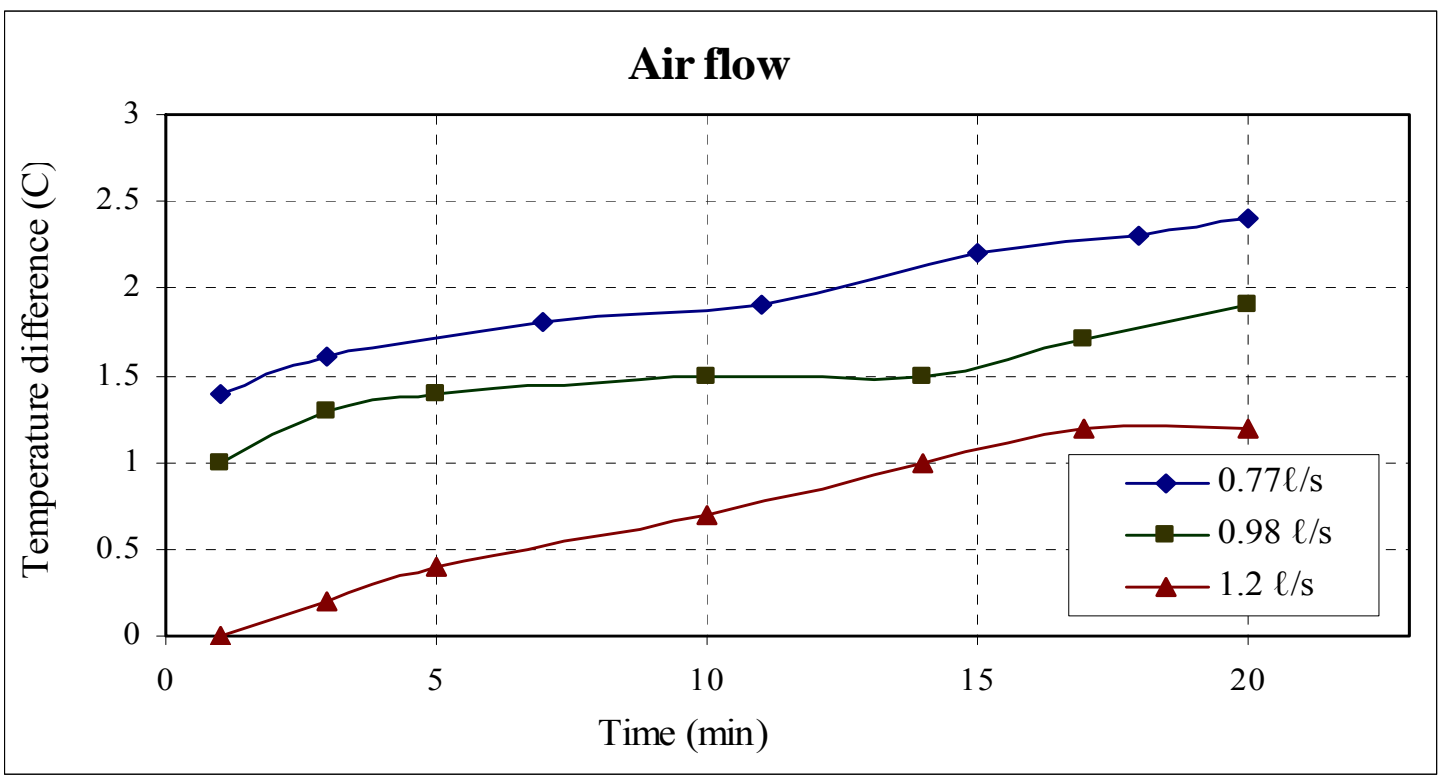

Fig.3. Effect of volumetric air flowrate between two idetical samples treated with emulsion paint and Al spray on temperature difference of a hot plate and background with time.

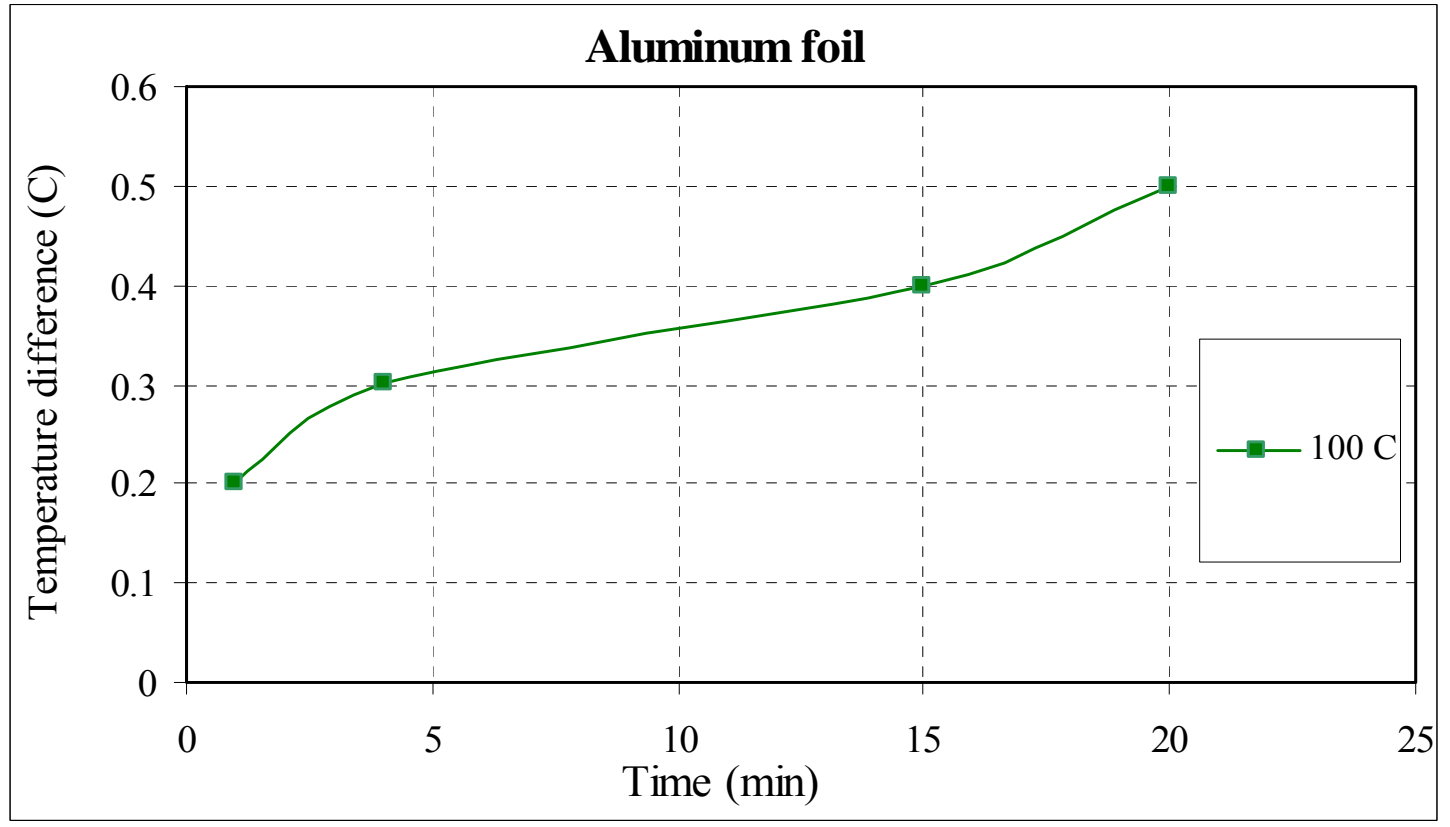

Fig.4. Effect of a singe Al foil sheet on temperature difference of a hot plate and background with time. 


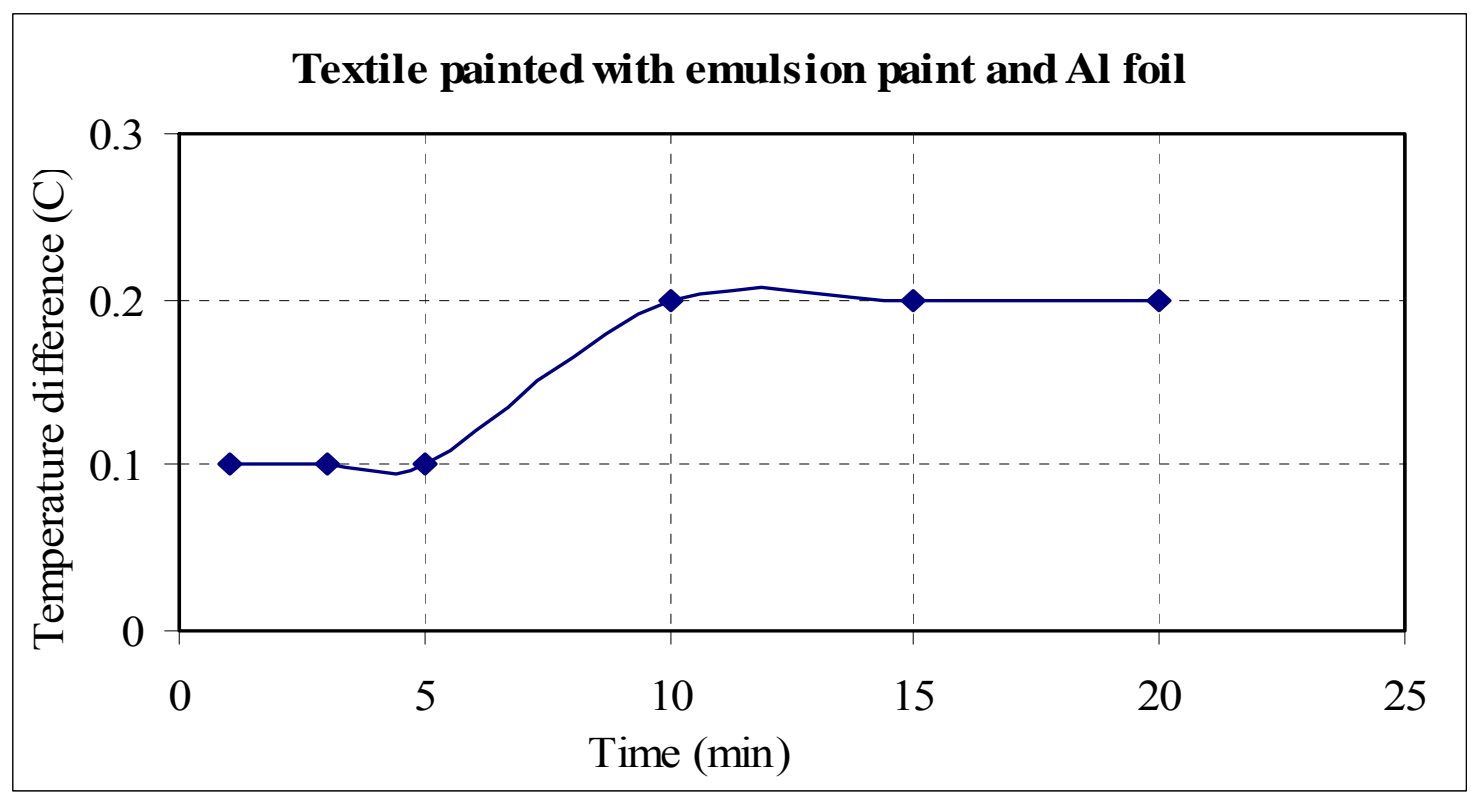

Fig.5. Effect of alminum foil sheet supported on a textile sample treated with plastic paint on temperature difference of a hot plate and background with time. 